\title{
ANALISIS PENGARUH LINGKUNGAN KERJA, KOMUNIKASI DAN FASILITAS KERJA TERHADAP SEMANGAT KERJA PEGAWAI KANTOR PERTANAHAN KABUPATEN PONOROGO
}

\author{
Yuswa Dolar Tri Sendik Aksa ${ }^{1}$ \\ Woro Utari ${ }^{2}$ \\ Mei Indrawati ${ }^{3}$ \\ Program Magister Manajemen \\ Universitas Wijaya Putra Surabaya ${ }^{1}$ \\ email: sendik.aksa19@gmail.com
}

\begin{abstract}
The purpose of this study was to describe the work environment, communication, work facilities, and morale at the Ponorogo Regency Land Office, to determine and analyze the influence of work environment, communication and work facilities on employee morale of the Ponorogo Regency Land Office. The population in this study were 93 employees of the Ponorogo Regency Land Office. The number of samples used in this study were 93 people. The data collection techniques used were questionnaires and documentation. The data analysis technique used Multiple Linear Regression. Based on the research results, it can be seen that the variables of communication, work facilities and morale in the Ponorogo Regency Land Office are in good categories, only work environment variables are in the good enough category. Work environment, communication and work facilities have a significant effect on the morale of employees of the Ponorogo Regency Land Office.
\end{abstract}

Keywords: Work Environment, Communication, Work Facilities, and Work Spirit.

\section{PENDAHULUAN}

Dalam mencapai tujuan seharusnya setiap instansi instansi, sumber daya manusia pemerintahan khusunya Kantor merupakan salah satu faktor yang Pertanahan Kabupaten Ponorogo menempati posisi strategis karena meningkatkan kualitas kerja segala aktifitas tidak lepas dari peran pegawainya dengan memperhatikan serta tenaga manusia. Setiap semangat kerjanya. Semangat kerja pekerjaan akan selalu dilaksanakan pegawai sangat penting dalam oleh pegawai, oleh karena itu pegawai menunjang tercapainya tujuan perlu diperlakukan dengan baik agar tetap bersemangat dalam bekerja. Banyak cara yang bisa dilakukan agar pegawai mau mendedikasikan seluruh kemampuannya demi kemajuan instansi tempat dia bekerja. Mengingat betapa pentingnya peranan sumber daya manusia, maka sudah instansi.

Salah satu upaya yang dapat dilakukan dalam meningkatkan semangat kerja adalah dengan menjaga dan memperhatikan lingkungan kerja agar tetap kondusif dan memberikan kenyamanan untuk semua pegawai. Lingkungan kerja 
memberikan pengaruh terhadap
meningkatnya semangat kerja
pegawai karena lingkungan kerja
merupakan segala sesuatu hal yang
berada di sekitar pegawai yang dapat
mempengaruhi pegawai dalam
melaksanakan tugas dan tanggung
jawabnya. Lingkungan kerja yang
baik dapat mendukung pelaksanaan
kerja yang efektif sehingga dapat
menimbulkan semangat dalam
bekerja. Seperti halnya pada hasil
penelitian yang dilakukan oleh
Bakhtiar (2017), Anggreni, dkk (2018) dan Khamri (2019) yang menyatakan bahwa Lingkungan Kerja berpengaruh signifikan terhadap Semangat Kerja. Akan tetapi hasil penelitian tersebut berbeda dengan hasil penelitian yang dilakukan oleh Basa, dkk. (2019) yang menyatakan bahwa lingkungan kerja tidak berpengaruh signifikan terhadap semangat kerja.

Selain dari lingkungan kerja, upaya lainnya dalam meningkatkan semangat kerja pegawai adalah dengan menerapkan komunikasi yang baik. Komunikasi merupakan salah satu fungsi dari manajemen yang penting, karena komunikasi merupakan penyampaian informasi dari seseorang kepada orang lain. Komunikasi juga merupakan pertukaran ide- ide dan informasi dua arah yang menuju tercapainya pengertian bersama. Komunikasi yang ada di Kantor Pertanahan Kabupaten Ponorogo masih belum berjalan secara maksimal, pegawai kebingungan untuk menerima informasi dengan baik karena banyaknya saluran yang harus dilalui seperti beberapa Kepala Sub Seksi dan beberapa Kepala Seksi, sehingga kemungkinan berubahnya informasi akan besar sehingga peagawai

menjadi kebingungan dalam
melaksanakan tugasnya dan pada akhirnya menurunkan semangat kerjanya. Perubahan tiap informasi cenderung akan diubah oleh sang penyampai sesuai dengan kepentinan pribadi. Padahal adanya komunikasi yang lancar akan dapat mendorong semangat kerja pegawai dalam bekerja untuk mewujudkan tujuan organisasi Seperti pada penelitian yang dilakukan oleh Murtisaputra dan Ratnasari (2018) yang menyatakan bahwa komunikasi secara parsial berpengaruh signifikan terhadap semangat kerja karyawan. Berbeda dengan hasil penelitian yang dilakukan oleh Sitanggang (2017) yang menyatakan bahwa komunikasi tidak terdapat pengaruh positif dan signifikan terhadap semangat kerja karyawan.

Selain lingkungan kerja dan komunikasi, dalam rangka meningkatkan semangat kerja pegawai Kantor Pertanahan Kabupaten Ponorogo hendaknya berupaya untuk meningkatkan semangat kerjanya seperti melalui penyediaan fasilitas yang kondusif. Fasilitas kerja yang kondusif selayaknya juga menjadi perhatian karena hal itu merupakan faktor yang berpengaruh terhadap semangat kerja pegawai. Seperti pada hasil penelitian yang dilakukan oleh Cahayani (2016) yang menyatakan bahwa ada Pengaruh Fasilitas Kerja terhadap Semangat Kerja Pegawai pada Swalayan Cahaya Melati Semarapura Klungkung. Akan tetapi hasil penelitian ini berbeda dengan hasil penelitian yang dilakukan oleh Bakhtiar (2017) yang menyatakan bahwa pengaruh fasilitas kerja terhadap semangat kerja pegawai tidak signifikan. 


\section{TINJAUAN PUSTAKA}

Semangat kerja merupakan seseorang keinginan untuk melakukan suatu pekerjaan dengan sungguhsungguh agar pkerjaan tersebut diharapkan dapat selesai lebih cepat dan lebih baik, sedangkan definisi gairah kerja merupakan persaaan senang yang mendalam pada pekerjaan yang sedang dikerjakan (Nitisemito dalam Putri, 2019). Semangat kerja juga dapat diartikan sebagai suatu kondisi batin atau perilaku seorang maupun sekelompok orang yang dapat memberikan rasa senang pada seorang peagwai dalam melaksanakan pekerjaannya menjadi lebih giat dan lebih tertib lagi untuk mencapai tujuan yang telah ditetapkan. (Siswanto, 2017). Beberapa indikator yang dapat digunakan dalam mengukur semangat kerja diantaranya adaah kehadiran pegawai di tempat kerja, kemauan pegawai dalam bekerja, kedisiplinan pegawai dalam bekerja, kesenangan maupun kepuasan pegawai dalam bekerja (Taufiq dalam Mayatopani, dan Nurfadilah, 2017: 92).

Menurut Nitisemito dalam Putri (2019) lingkungan kerja dapat diartikan sebagai segala sesuatu pada sekitaran tempat pegawai tersebut bekerja, dimana hal tersebut dapat memberikan pengaruh kepada pegawai dalam menyelesaikan pekerjaannya. Sedarmayanti (2017:36) menjelaskan ada beberapa indikator yang mempengaruhi lingkungan kerja yang kemudian sudah penulis sesuaikan dengan keadaan di lokasi tempat penelitian diantaranya: Penerangan atau pencahayaan yanga ada di sekitar tempat pegawai tersebut bekerja, temperatur yang ada di tempat pegawai tersebut bekerja, sirkulasi udara yang ada di tempat pegawai tersebut bekerja, kebisingan yang ada di tempat pegawai tersebut bekerja, hubungan pegawai dengan sesama rekan kerja, maupun hubungan atasan terhadap para bawahannya dan kerjasama antara pegawai yang satu dengan pegawai lainnya.

Sopia dalam Azwar (2016) mengemukakan komunikasi sebagai penyampaian maupun sebagai pertukaran informasi antara pengirim dengan penerima informasi baik dilakukan secara lisan, tulisan ataupun dengan menggunakan berbagai peralatan komunikasi yang ada. Pendapat lain disampaikan oleh Robbins and Judge (2016) yang mengemukakan bahwa komunikasi merupakan penyampaian suatu pesan dari satu orang ke orang yang lainnya yang saling paham makna dari apa yang sudah disampaikan tersebut adapun indikator komunikasi menurut pejelasan dari Umam (2018) diantaranya adalah kejelasan apa yang disampaikan, ketepatan informasi, isi konteks informasi dan alur informasi yang disampaikan.

Moenir (2015) menjelaskan Fasilitas kerja merupakansuatu yang dapat ditempati maupun diminati pegawai dalam hal untuk memperlancar pekerjaan pegawai dalam menyelesaikan pekerjaannya. Sedangkan hasibuan (2016) menjelaskan fasilitas kerja merupakan suatu alat yang dapat digunakan oleh pegawai dalam hal memudahkan pegawai tersebut melaksanakan pekerjaan sehari-hari agar pekerjaan tersebut cepat selesai. Indikator mengenai fasilitas kerja menurut Moenir (2015) antara lain sebagai berikut: peralatan kerja seperti mesin computer dan mesin cetak, perlengkapan kerja seperti 
perlengkapan komunikasi dan furniture (meja, kursi, rak, lemari $\mathrm{dsb}$ ), perlengkapan bantu atau fasilitas seperti mesin pendingin ruangan (kipas, AC) dan mesin absensi.

\section{METODE PENELITIAN}

Penelitian ini termasuk dalan penelitian yang berjenis eksplanatory. Sedangkan pendekatan dalam penelitian ini termasuk dalam penelitian dengan pendekatan kuantitatif. Populasi pada penelitian ini mengambil dari seluruh Pegawai yang ada di Kantor Pertanahan Kabupaten Ponorogo dengan jumlah sebanyak 93 orang. Kemudian jumlah sampel yang digunakan pada penelitian ini juga sama menggunkan 93 orang karena menggunkan teknik pengambilan sampling dengan total atau sensus sampling. Teknik pengumpulan data yang digunakan adalah kuesioner dan dokumentasi. Sedangkan teknik yang digunakan untuk analisis data dalam penelitian ini dengan menggunakan pengujian statistik dengan alat bantu sotfware SPSS dan agar dapat diketahui pengaruh variabel bebas terhadap variabel terikatnya dengan menggunkan teknik analisis Regresi Linier Berganda.

\section{HASIL DAN PEMBAHASAN Hasil Analisis Deskriptif}

Untuk mengetahui deskripsi setiap variabel peneliti dapat digunakan analisis descriptive statistic. Pada hasil descriptive statistic variabel bebsar lingkungan kerja, komunikasi dan fasilitas kerja serta variabel terikat semangat kerja, yang dapat dijelaskan pada tabel sebagai berikut

Tabel 1

Descriptive Statistics

\begin{tabular}{lrrrrr}
\hline \multicolumn{1}{c}{ Variable } & N & Minimum & Maximum & Mean & $\begin{array}{c}\text { Std. } \\
\text { Deviation }\end{array}$ \\
\hline Lingkungan & 93 & 1.57 & 4.43 & 3.2130 & .43962 \\
\hline Komunikasi & 93 & 2.25 & 5.00 & 3.5726 & .58116 \\
\hline Fasilitas kerja & 93 & 1.83 & 4.83 & 3.4680 & .53719 \\
\hline Semangat kerja & 93 & 2.40 & 4.40 & 3.4860 & .42976 \\
\hline
\end{tabular}

Sumber : Hasil Analisis Data, diolah (2021)

Berdasarkan data pada tabel tersebut tersebut dapat diketahui variabel lingkungan kerja memiliki nilai rata-rata atau mean sebesar 3.2130 dalam kategori cukup baik, variabel komunikasi belajar memiliki nilai rata-rata atau mean sebesar 3.5726 dalam kategori baik, variabel fasilitas kerja memiliki nilai rata-rata atau mean sebesar 3.4680 dalam kategori baik, dan variabel semangat kerja memiliki nilai rata-rata atau mean sebesar 3.4860 dalam kategori baik.

\section{Analisis Regresi Linier Berganda}

Selanjutnya hasil analisis regresi liner berganda dalam penelitian ini dengan menggunakan SPSS dapat diperoleh hasil yang dapat dijelaskan pada tabel sebagai berikut 
Journal of Applied Management and Accounting Science. (JAMAS)

(Yuswa Dolar Tri Sendik Aksa, Woro Utari, Mei Indrawati 84 - 92)

Vol 2, No 2, Juni 2021

\begin{tabular}{|c|c|c|c|c|c|}
\hline \multicolumn{6}{|c|}{$\begin{array}{c}\text { Tabel } 2 \\
\text { Hasil Analisis Regresi Linier Berganda }\end{array}$} \\
\hline \multirow[t]{2}{*}{ Model } & \multicolumn{2}{|c|}{$\begin{array}{c}\text { Unstandardized } \\
\text { Coefficients } \\
\end{array}$} & \multirow{2}{*}{$\begin{array}{c}\text { Standardized } \\
\text { Coefficients }\end{array}$} & \multirow[t]{2}{*}{$\mathrm{t}$} & \multirow[t]{2}{*}{ Sig. } \\
\hline & B & Std. Error & & & \\
\hline 1 (Constant) & 1.192 & .335 & & 3.560 & .001 \\
\hline Lingkungan kerja & .259 & .091 & .265 & 2.837 & .006 \\
\hline Komunikasi & 244 & .070 & .329 & 3.475 & .001 \\
\hline Fasilitas kerja & .170 & .071 & .213 & 2.386 & .019 \\
\hline
\end{tabular}

Sumber : Hasil Analisis Data, diolah (2021)

Berdasarkan pada hasil analisis regresik linier berganda tersebut, maka dapat dimasukkan dalam persamaan regresi linier berganda berikut:

$$
\begin{aligned}
\mathrm{Y}=1.192 & +0.259\left(\mathrm{X}_{1}\right)+0.244\left(\mathrm{X}_{2}\right) \\
& +0.170\left(\mathrm{X}_{3}\right)
\end{aligned}
$$

Pada persamaan regresi linier tersebut di atas dapat diketahui bahwa ada pengaruh yang positif dari lingkungan kerja, komunikasi,dan fasilitas kerja terhadap semangat kerja. Nilai konstanta 1.192 dapat menjelaskan jika tidak ada variabel bebas lingkungan kerja dan komunikasi, serta fasilitas kerja, maka nilai semangat kerja dapat diketahui sebesar 1.192 satuan. Pada nilai konstanta variabel lingkungan kerja sebesar 0.259 menjelaskan jika ada kenaikan pada lingkungan kerja sebesar satu satuan maka semangat kerja juga akan mengalami peningkatan sebesar 0.259 karena bernilai positif. Pada nilai konstanta variabel komunikasi sebesar 0.244 menjelaskan jika ada kenaikan pada komunikasi sebesar satu satuan maka semangat kerja juga akan mengalami peningkatan sebesar 0.244 karena bernilai positif. Pada nilai konstanta variabel fasilitas kerja sebesar 0.170 menjelaskan jika ada kenaikan pada fasilitas kerja sebesar satu satuan maka semangat kerja juga akan mengelami peningkatan sebesar 0.170 karena bernilai positif.

Uji t

Kemudian untuk mengetahui seberapa besar pengaruh lingkungan kerja dan komunikasi serta fasilitas kerja secara sendiri-sendiri atau secara parsial terhadap semangat kerja pegawai akan dijelaskan pada tabel sebagai berikut

Tabel 3

Hasil Uji t

\begin{tabular}{llr}
\hline \multicolumn{1}{c}{ Model } & t & Sig. \\
\hline 1 (Constant) & 3.560 & .001 \\
Lingkungan kerja & 2.837 & .006 \\
Komunikasi & 3.475 & .001 \\
Fasilitas kerja & 2.386 & .019 \\
\hline
\end{tabular}

Sumber : Hasil Analisis Data, diolah (2021) 


\begin{abstract}
Berdasarkan pada hasil analisis uji $t$ tersebut di atas, maka dapat dijelaskan pengujian hipotesis secara parsial (uji t) yang dapat dilihat dari nilai $\mathrm{t}$ hitung pada variabel lingkungan kerja dengan nilai sebesar 2.837 yang memiliki signifikansi 0.006 , nilai signifikansi tersebut masih lebih kecil dari pada 0,05, sehingga dapat dikatakan bahwa lingkungan kerja berpengaruh secara signifikan terhadap semangat kerja pegawai Kantor Pertanahan Kabupaten Ponorogo. dengan arah yang positif. Selanjutnya didapatkan juga nilai $\mathrm{t}$ hitung pada variabel komunikasi dengan nilai sebesar 3.475 yang memiliki signifikansi 0.001, nilai signifikansi tersebut masih lebih kecil dari pada 0,05, sehingga dapat dikatakan bahwa komunikasi berpengaruh secara signifikan terhadap semangat kerja
\end{abstract}

\begin{abstract}
pegawai Kantor Pertanahan Kabupaten Ponorogo dengan arah yang positif. Kemudian juga didapatkan nilai t hitung pada variabel fasilitas kerja dengan nilai sebesar 2.386 yang memiliki signifikansi 0.019 , nilai signifikansi tersebut masih lebih kecil dari pada 0,05, sehingga dapat dikatakan bahwa fasilitas kerja berpengaruh secara signifikan terhadap semangat kerja pegawai Kantor Pertanahan Kabupaten Ponorogo dengan arah yang positif.
\end{abstract}

\section{Koefisien Determinasi $\left(\mathbf{R}^{\mathbf{2}}\right)$}

Besarnya konstribusi pengaruh lingkungan kerja dan komunikasi serta fasilitas kerja terhadap variabel bebas semangat kerja pegawai pada Kantor Pertanahan Kabupaten Ponorogo dapat dijelaskan dalam tabel berikut :

Tabel 4

Model Summary

\begin{tabular}{lrrrr}
\hline Model & R & $\begin{array}{c}\text { R } \\
\text { Square }\end{array}$ & $\begin{array}{c}\text { Adjusted R } \\
\text { Square }\end{array}$ & $\begin{array}{c}\text { Std Error of } \\
\text { the estimate }\end{array}$ \\
\hline 1 & $.601^{\mathrm{a}}$ & .361 & .339 & .34934 \\
\hline
\end{tabular}

Sumber : Hasil Analisis Data, diolah (2021)

Hasil analisis data menunjukkan bahwa koefisien determinasi adalah sebesar 0.601 atau kalau dijadikan prosentase sebesar $60.1 \%$. Hal ini dapat menjelaskan bahwa sebesar $60.1 \%$ semangat kerja pegawai Kantor Pertanahan Kabupaten Ponorogo dapat dijelaskan atau dapat dipengaruhi oleh variabel lingkungan kerja dan komunikasi serta fasilitas kerja. Kemudian sisanya yanga sebesar $39.9 \%$ semangat kerja pegawai Kantor Pertanahan Kabupaten Ponorogo dapat dijelaskan oleh variabel lain diluar penelitian ini.

\section{Pembahasan}

Dari hasil analisis pengujian deskriptif yang dilakukan pada semua variabel dalam penelitian ini dapat dijelaskan bahwa variabel lingkungan kerja berada pada kategori yang cukup baik, kemudian pada variabel komunikasi berada pada kategori yang baik,selanjutnya variabel fasilitas kerja berada pada kategori yang baik dan variabel semangat kerja juga berada pada kategori yang baik sehingga dapat disimpulkan bahwa variabel komunikasi, fasilitas kerja dan semangat kerja di Kantor Pertanahan Kabupaten Ponorogo, 
semuanya berada pada kategori yang baik, hanya saja pada variabel lingkungan kerja yang berada pada kategori yang cukup baik.

Dari hasil analisis uji $\mathrm{t}$ yang telah dilakukan pada variabel lingkungan kerja ternya memilki pengaruh yang signifikan terhadap semangat kerja pegawai Kantor Pertanahan Kabupaten Ponorogo dengan arah pengaruhnya yang positif, sehingga apabila ada perubahan pada variabel lingkungan kerja akan dengan signifikan berpengaruh pada perubahan semangat kerja pegawai Kantor Pertanahan Kabupaten Ponorogo. Hasil penelitian yang telah dilakukan ini dapat mendukung hasil penelitian yang telah dilakukan oleh Bakhtiar (2017) yang menyatakan dari hasil uji t lingkungan kerja terhadap semangat karyawan diperoleh sebesar 2,616. Artinya, lingkungan kerja terhadap semangat karyawan adalah signifikan, sama halnya pada penelitian yang telah dilakukan oleh Anggreni, dkk. (2018) yang menyatakan bahwa lingkungan kerja berpengaruh positif dan signifikan terhadap semangat kerja karyawan, Khamri (2019) juga menyatakan hal yang sama dalam hasil penelitiannya bahwa Lingkungan Kerja berpengaruh signifikan secara parsial terhadap Semangat Kerja Pegawai Dinas Kesehatan Kabupaten Dharmasraya.

Dari hasil analisis uji $\mathrm{t}$ yang telah dilakukan pada variabel komunikasi juga didapatkan hasil yang berpengaruh signifikan terhadap semangat kerja pegawai Kantor Pertanahan Kabupaten Ponorogo. Apabila ada perubahan pada variabel komunikasi ini akan berpengaruh pada peningkatan atau penurunan semangat kerja pegawai Kantor
Pertanahan Kabupaten Ponorogo. Hasil yang telah didapatkan pada penelitian ini dapat mendukung hasil penelitian yang telah dilakukan Murtisaputra dan Ratnasari (2018) yang menjelaskan bahwa komunikasi secara parsial memiliki pengaruh yang signifikan terhadap semangat kerja karyawan.

Berdasarkan hasil analisis data juga didapatkan bahwa variabel fasilitas kerja juga berpengaruh signifikan terhadap semangat kerja pegawai Kantor Pertanahan Kabupaten Ponorogo. Hal ini dapat menjelaskan bahwa apabila ada perubahan pada variabel fasilitas kerja ini akan berpengaruh pada perubahan semangat pegawai di Kantor Pertanahan Kabupaten Ponorogo. Dari hasil penelitian ini juga dapat mendukung penelitian yang telah dilakukan oleh Cahayani (2016), dimana hasil penelitiannya menyatakan bahwa ada Pengaruh Fasilitas Kerja terhadap Semangat Kerja Pegawai pada Swalayan Cahaya Melati Semarapura Klungkung.

Berdasarkan hasil analisis koefisien determinasi juga dapat dijelaskan bahwa semangat kerja pegawai Kantor Pertanahan Kabupaten Ponorogo dapat dipengaruhi oleh variabel lingkungan kerja dan komunikasi serta fasilitas kerja dengan besar lebih dari 50\% hal ini sudah bagus, dimana sisanyasemangat kerja dapat dipengaruhi oleh varibel lain diluar lingkungan kerja dan komunikasi serta fasilitas kerja yang ada pada penelitian ini. 


\section{SIMPULAN DAN SARAN \\ Simpulan}

Berdasarkan pada hasil analisis dan pembahasan seperti yang sudah diuraian di atas, maka dapat disimpulkan sebagai berikut :

1. Variabel komunikasi, fasilitas kerja dan semangat kerja di Kantor Pertanahan Kabupaten Ponorogo, semuanya berada pada kategori yang baik, hanya saja pada variabel lingkungan kerja yang berada pada kategori yang cukup baik.

2. Lingkungan Kerja memiliki pengaruh yang signifikan terhadap semangat kerja pegawai Kantor Pertanahan Kabupaten Ponorogo dengan nilai signifikansi sebesar 0.006 masih di bawah 0.05 .

3. Komunikasi berpengaruh signifikan terhadap semangat kerja pegawai Kantor Pertanahan Kabupaten Ponorogo dengan nilai signifikansi sebesar 0.001 . dengan nilai signifikansi tersebut komunikasi menjadi variabel yang paling berpengaruh terhadap semangat kerja dari pada variabel lingkungan dan fasilitas kerja

4. Fasilitas kerja berpengaruh signifikan terhadap semangat kerja pegawai Kantor Pertanahan Kabupaten Ponorogo dengan besarnya nilai signifikansi yang hanya didapatkan sebesar 0.019 masih di bawah 0.05 .

\section{Saran}

Berdasarkan ada hasil penelitian yang telah dilakukan, maka saran yang dapat diberikan adalah sebagai berikut :

1. Komunikasi memiliki pengaruh yang signifikan dan yang paling dominan terhadap semangat kerja pegawai Kantor Pertanahan

Kabupaten Ponorogo, oleh karena itu perlu adanya peningkatan pada komunikasi agar semangat kerja juga dapat meningkat. Upaya yang dapat dilakukan dengan cara penggunaan bahasa yang tepat konteksnya dengan suasana dan keadaan karena dan juga perlu perbaikan pada peggunaan alur bahasa yang baik, tidak berbelitbelit.

2. Selain komunikasi, lingkungan kerja dan fasilitas kerja juga perlu untuk ditingkatkan karena juga memiliki pengaruh yang signifikan terhadap semangat kerja pegawai Kantor Pertanahan Kabupaten Ponorogo. Upaya yang dapat dilakukan berkaitan dengan lingkungan kerja adalah lebih menjalin hubungan yang lebih baik lagi atasan dengan bawahannya dan kerjasama dalam penyelesaian pekerjaan. Upaya yang dapat dilakukan berkaitan dengan fasilitas kerja adalah perbaikan pada mesin pendingin ruangan dan mesin absensi agar dapat berfungsi lebih baik.

\section{DAFTAR PUSTAKA}

Anggreni, Ni Wayan; Sitiari, Ni Wayan; Indiani, Ni Luh Putu and Pertamawati, Ni Putu. 2018. The Effect of Leadership and Work Environment on Employee Performance Through Mediation of Work Spirit at Prama Sanur Beach Hotel. Jurnal Ekonomi dan Bisnis Jagaditha Volume 5, Nomor 2, 2018, pp. 84-91 
Azwar, Saifuddin. 2016. Sikap dan Perilaku. Yogyakarta: Pustaka Pelajar.

Bakhtiar. 2017. Pengaruh Fasilitas Dan Lingkungan Kerja Terhadap Semangat Kerja Karyawan Pada Bank SumutMedan. Jurnal Riset Manajemen \& Bisnis (JRMB), Vol. 2. No. 3. Oktober 2017

Basa, Firna Amelia Mosa; Djailani, Abd. Kodir dan Khoirul ABS, M. 2019. Pengaruh Lingkungan Kerja Dan Disiplin Kerja Terhadap Semangat Kerja Karyawan. e - Jurnal Riset Manajemen Prodi Manajemen Fakultas Ekonomi Unisma

Cahayani, Ni Luh Putu. 2016. Pengaruh Gaji, Fasilitas Kerja, Dan Motivasi Kerja Terhadap Semangat Karyawan Pada Swalayan Cahaya Melati. Vol. 04. NO. 1 Februari 2016.

Khamri, Aprial. 2019. The Influence Of The Work Environment, Work Discipline On The Spirit Of Work And Its Impact On Employee Performance At The Dharmasraya District Health Office Archives of Business Research - Vol.7, No.5

Mayatopani, Hendra dan Nurfadilah, Siti. 2017. Analisa Design SI/TI Pengelola Surat Berbasis Web Pada Kantor Kecamatan Pakuhaji di Kabupaten Tangerang
Moenir, H.A.S. 2015. Manajemen Pelayanan Umum Di Indonesia. Jakarta: Bumi Aksara.

Murtisaputra, Eko dan Ratnasari, Sri Langgeng. 2018. Pengaruh Lingkungan Kerja, Insentif, Komunikasi Dan Senioritas Terhadap Semangat Kerja Karyawan. Jurnal Dimensi, Vol. 7, No. 3 : 434-453 November 2018

Putri, Ni Made Dewi Kansa. 2019. Peran Semangat Kerja Memediasi Pengaruh Lingkungan Kerja Terhadap Kinerja Pegawai Dinas Kesehatan Kabupaten Tabanan, Bali. Jurnal Widya Manajemen Vol. 1, No. 2, Agustus 201960

Robbins, Stephen P., Timothy A. Judge. 2016. Perilaku Organisasi Edisi 16. Jakarta : Salemba Empat.

Sedarmayanti. 2017. Manajemen Sumber Daya Manusia. Bandung: Refika. Aditama.

Sitanggang, Manahan Kardy. 2016. Pengaruh Kompensasi Dan Komunikasi Terhadap Semangat Kerja Karyawan Pada PT. BAF Cabang Medan. Jurnal Multi Sains. Maret 2016 